\title{
Max Weber: o processo de racionalização e 0 desencantamento do trabalho nas organizações contemporâneas*
}

\author{
Hermano Roberto Thiry-Cherques**
}

Sumário: 1 . O espírito do trabalho: Weber e a racionalização; 2 . As racionalidades; 3. Racionalidade e ação; 4. A racionalização; 5 . O processo histórico; 6 . O trabalho ascético; 7. O trabalho burguês; 8. O trabalho desencantado; 9. Especialistas sem coração.

Summary: 1 . The spirit of labor: Weber and rationalization; 2. The rationalities; 3. Rationality and action; 4. Rationalization; 5. The historical process; 6. Ascetic work; 7. Bourgeois work; 8. Disenchanted work; 9. Heartless specialists.

Palavras-chave: Weber; racionalização; trabalho; desencantamento.

KEY WORDS: Weber; rationalization; work; labor; disenchantment.

Este artigo indica algumas implicações do pensamento weberiano sobre a compreensão do trabalho e da forma de administrá-lo. Com base nos conceitos weberianos de racionalidade e de racionalização, é feita uma apreciação do trabalho na história ocidental, com ênfase no momento da passagem do capitalismo tradicional para o contemporâneo. A tese central é a de que as teorias de Weber são um modo válido para compreender o trabalho desencantado da atualidade.

Max Weber: rationalization process and the disenchantment of work in contemporary organizations

This article discusses some implications of Weber's thoughts about understanding and managing labor. Based on Weber's concepts of rationality and rationalization, the article develops an account of the transformations of labor in Western history, stressing the shift from early to contemporary capitalism. The central thesis is that Weber's theories are a well grounded way to explain today's disenchanted work.

\footnotetext{
* Artigo recebido em nov. 2008 e aceito em mar. 2009.

** Professor titular da Escola Brasileira de Administração Pública e de Empresas (Ebape/FGV). Endereço: Praia de Botafogo, 190, 5o andar - Botafogo - CEP 22250-900, Rio de Janeiro, RJ, Brasil. E-mail: Hermano.roberto@fgv.br.
} 


\section{0 espírito do trabalho: Weber e a racionalização}

Max Weber demonstrou como o progresso da civilização no Ocidente foi regido por uma redução à lógica da vida social. Explicou que a modernidade não só deriva da diferenciação da economia capitalista e do Estado, mas também de uma reordenação racional da cultura e da sociedade.

A presença do pensamento de Weber nos estudos organizacionais se dá, no caso brasileiro, a partir de três frentes principais: a da absorção dos processos analíticos da sociologia interpretativa (verstehende soziologie), a discussão do formalismo burocrático e a dos sistemas de poder e sujeição internos às organizações. Marco da apropriação de Weber às questões da gestão do trabalho é a obra de Raimundo Faoro que, em 1958, constrói uma estrutura explicativa a partir da análise do patrimonialismo e da categoria weberiana de estamento. Em meados do século passado, Alberto Guerreiro Ramos chama a atenção para temas como a reificação e a alienação dos trabalhadores. Trabalhos mais recentes, como os de Paulo Roberto Motta, que trata do ponto de vista gerencial; e de Fernando Tenório, que refere à importância do modelo weberiano no entendimento das organizações; e Thiry-Cherques na esfera da gestão de pessoas, são complementados pela discussão metodológica presente em Sérgio Alves.

Neste artigo discuto os efeitos da redução sobre o entendimento do trabalho e da forma de administrá-lo. A partir da distinção entre racionalidade finalística e valorativa, examino o processo histórico de racionalização, tal como relatado por Weber, especialmente na análise da forma como a passagem do trabalho ascético para o trabalho burguês desembocou no trabalho sem encanto da atualidade. Concluo com uma apreciação das dificuldades apresentadas pelo espírito do trabalho na atualidade, cindido entre uma concepção pragmática, do trabalho-valor, característico da prática racional, e o entendimento do valor-trabalho, próprio da ética econômica racional. O ponto focal do artigo é o da contribuição de Weber para o mal-estar do trabalho contemporâneo, espoliado da espiritualidade pela tecnificação, pela alienação e pela rotinização, privado do seu caráter emancipador pela impossibilidade da autorrealização.

A orientação metodológica de Weber é de que a realidade não pode ser reduzida a nenhum esquema conceitual. Há duas razões para isso, que ele chamou de hiatus irracionalis entre a realidade e o conceito: a realidade é concreta, individual e definida pela singularidade de suas propriedades, enquanto o conceito é necessariamente abstrato e geral; a realidade é infinitamente complexa, tanto quantitativa quanto qualitativamente, de forma que nenhum 
conceito pode abarcá-la. Weber é particularmente difícil porque utiliza conceitos sem lhes atribuir uma definição geral. O seu esquema analítico envolve a construção de conceitos. Não há definição prévia porque ele chega às definições ao cabo de longos raciocínios.

\section{As racionalidades}

Weber trata da racionalidade principalmente nos dois capítulos iniciais da parte I de Economia e sociedade. Ali ele distingue a racionalidade formal da substantiva e define a diferença entre a racionalidade meio finalística e a racionalidade quanto aos valores.

Segundo a denominação de Weber, a racionalidade formal é constituída pela calculabilidade e predicabilidade dos sistemas jurídico e econômico. No campo das organizações, a racionalidade formal está presente em aparelhos como o contábil e o burocrático. Implica regras, hierarquias, especialização, treinamento. A racionalidade substantiva é relativa ao conteúdo dos fins operacionais dos sistemas legal, econômico e administrativo. Difere da formal por ter uma lógica estabelecida em função dos objetivos e não dos processos.

A segunda distinção, entre as racionalidades meio finalística e valorativa, deriva do fato de existirem vários tipos de ações e cada tipo corresponde a um grau de maior ou menor racionalidade. A ação que é racional quanto aos fins que se propõe a alcançar, a ação que é racional quanto aos meios empregados, a ação "afetiva", que é racional quanto aos sentimentos, a ação tradicional que está próxima da irracionalidade, já que fundada unicamente no hábito. De modo que um comportamento racional não precisa, necessariamente, obedecer a uma lógica finalística. Pode ser "valor-racional", sempre que seus fins ou seus meios sejam religiosos, morais ou éticos e não diretamente ligados à lógica formal, à ciência ou à eficiência econômica.

Valor para Weber é a imaginação de uma validade que se torna motivo de uma ação. $\mathrm{O}$ termo validade tendo o sentido tanto de norma de validade quanto de pretensão de validade. Não há somente uma alternativa entre valores, mas uma luta inconciliável, da qual não tomamos consciência. Quem quer conduzir sua vida de forma consciente é forçado a afirmar certos valores e a negar outros.

Weber define a racionalidade quanto aos valores da constatação de que a vida é inevitavelmente perpassada pelo irracionalismo do mundo, com o qual deve constantemente lidar. Um dos aspectos desse irracionalismo, que Weber batizou de politeísmo de valores, decorre do completo isolamento espi- 
ritual do ser humano no tocante ao sentido de sua vida, isto é, às escolhas das ordens de valores que pretende adotar e aos ideais pelos quais deseja lutar. Esse não finalismo, ou racionalidade quanto a valores, está preso às convicções e à religião e não deve ser confundido com a irracionalidade.

Os valores não são demonstráveis por métodos da ciência: só podem ser objeto da compreensão (verstehend). Só que não há valores que possam ser ditos "superiores" a outros: a hierarquia dos valores é cultural, no sentido contemporâneo do termo. Nem tudo que não é racional recai, necessariamente, na irracionalidade. Uma coisa, diz Weber (1950), "nunca é irracional por ela mesma, mas somente quando considerada a partir de um determinado ponto de vista". O nível de racionalidade de uma convicção é dado pelo distanciamento em relação à lógica social em que se vive, o de cada religião é dado pelo distanciamento que apresenta da magia e por sua coerência interna, e assim por diante. Por exemplo, ele atribui ao judaísmo uma "grande importância para o capitalismo racional moderno, (por ter transmitido) ao cristianismo sua hostilidade à magia". ${ }^{1}$

A racionalidade quanto aos valores situa-se no domínio do extracientífico, referindo-se aos fins a que os conhecimentos e meios engendrados pela racionalidade valorativa devem servir. Estes fins são produto de escolhas que têm por base valores não diferenciáveis objetivamente. Já a racionalidade meio finalística se encontra em polo oposto ao da racionalidade quanto aos valores. Ela é utilitária. Destina-se a formular o conhecimento a ser posto a serviço de um determinado fim que, contudo, não lhe diz respeito.

Isso significa que há um campo do racional e do não racional que nada tem a ver com a maximização. A análise do que se passa no âmbito das organizações concorda com essa perspectiva. Ao se examinar o trabalho e as formas de administrá-lo, o que se verifica é a co-habitação de várias racionalidades que eventualmente buscam a maximização, mas que também buscam o equilíbrio, a estabilidade, a inversão de sentidos, o repouso.

Dessa distinção vem a permanente atualidade de Weber. O entendimento da racionalidade meio finalística é impositivo para a compreensão de como o trabalho se constitui em meio para a obtenção de certos objetivos considerados desejáveis, como status, poder, recompensas materiais, integração social, realização pessoal e assim por diante. O entendimento da racionalidade quanto aos valores é essencial para a compreensão das razões, causas e condições que levam à apreciação valorativa desses fenômenos. De como e por

\footnotetext{
${ }^{1}$ Max Weber (1968).
} 
que atribuímos valor a posições de status, ao poder, à recompensa material, à integração social, à realização pessoal e assim por diante.

Somos os indivíduos nascidos dentro dos mecanismos da ordem econômica da produção. A racionalidade deveria governar o trabalho e a vida social. Mas não é o que acontece. Ao contrário, como demonstrou Weber, a determinação dos fins pessoais é dada pela experiência da vida e pela forma como se comportam os demais. Não há como estabelecer universalmente porque certos fins seriam considerados "racionais" e outros não. As pessoas, as sociedades e as culturas são extremamente complexas. Isso quer dizer que a racionalidade da vida e do trabalho não existe em estado puro. Ela deriva de um sistema de preferências, de escolhas, mas não de uma lógica absoluta quanto aos valores (a dedicação é preferível à indolência, mas não é mais racional do que ela), nem de uma lógica incondicional quanto aos fins almejados (o trabalho aturado raramente enriquece alguém).

\section{Racionalidade e ação}

A racionalidade não deve ser confundida com a ação social. Existem ações sociais que nada têm a ver com processos conscientes, derivados da vida afetiva e das tradições, como existem ações conscientes, "racionais", fundadas em aspectos não racionais, derivados da história e da subjetividade humanas. A racionalização e a ação racional são distintas. A racionalização oferece as condições em que ação é exercida. A racionalização é o processo que confere significado à diferenciação de linhas de ação. Embora uma ação seja racionalizável no interior de cada esfera, não é possível uma racionalidade total. O mundo não é racionalizável como um todo. As tensões entre racionalidade formal e substantiva são irredutíveis. A racionalidade formal, de cálculo meiosfins e a racionalidade substantiva, voltada para a efetivação de um valor, são irreconciliáveis. Ademais uma modalidade de ação racional em uma esfera pode ser irracional em outra. O cálculo econômico é racional para a esfera do mercado, mas não para a esfera do social.

A racionalidade finalística tem uma vertente prática, substantiva, referida ao domínio das rotinas, aos objetivos "naturais" do cotidiano. Seu processo mental é o cálculo meio-fim. A segunda vertente da racionalidade finalística é formal, institui diretamente normas de ação social. Informa sobre os padrões e regularidades de cada época e lugar. Seu processo mental é o do cálculo e da validação da norma. 
A racionalidade quanto aos valores tem uma face teórica, referida às normas de ação social legitimadas. Volta-se para o problema teórico e de validação. Seu processo mental é o cognitivo abstrato ou das ideias. A outra face da racionalidade quanto aos valores é substantiva: estabelece a coordenação entre os valores e a realidade. Seu processo mental é o da conscientização dos padrões e das regularidades espaço-temporais.

\section{A racionalização}

Na sociedade moderna, o trabalho se submete a controles e aspira a fins tidos como racionais que não podem distinguir-se dos meios necessários para atingi-los. O que rege o trabalho são racionalizações, não a supremacia dos princípios racionais.

A clareza dos conceitos de racionalidade e de racionalização é aparente. O próprio Weber é responsável pela falta de rigor que envolve a análise da racionalidade e dos processos de racionalização. Ele trata os dois temas fragmentariamente, sob óticas diversas, em mais de 100 passagens distintas e em nenhuma delas oferece uma definição rigorosa das duas noções.

Em linhas gerais, entende-se que o termo racionalização, como utilizado por Weber, significa a redução à racionalidade de todos os aspectos da vida social. A racionalização é um processo: o mais das vezes trata-se de uma sublimação, quando a ação emotivamente condicionada aparece como descarga consciente de um estado sentimental. Weber aplica o termo sublimação no sentido da química, da passagem de um estado sólido imediatamente ao gasoso e não no sentido que a psicanálise lhe daria mais tarde. Para ele, a sublimação corresponde ao trânsito sem mediação entre dois estados. Já para a psicanálise é o processo de tornar racional o ilógico, a explicação que visa tornar coerente ou moralmente aceitáveis atos, ideias ou sentimentos cujos motivos verdadeiros o indivíduo não percebe. Para Weber é o processo de ordenação daquilo que, sob a ótica da cultura ocidental, se encontra distribuído aleatoriamente, do não econômico, do estado "natural" das coisas.

Já a racionalidade é para Weber tanto explanandum, a explicação dos processos sociais, quanto explanans, a racionalização do mundo desencadeada por esses processos. Ele reconheceu na racionalização o avanço do processo civilizatório, mas também as sementes da perda da individualidade e da liberdade identitária. Denunciou a irracionalidade substantiva da racionalização do comportamento social. Justificou a rebeldia contra quem pretenda padronizar a vida em comum, seja politicamente, mediante o Estado totalitário, 
seja socialmente, por meio do pensamento único, da conduta "correta" ou da moda. Mas ele também se refere à racionalização como adaptação deliberada dos costumes e das tradições, como um elo entre ideais e interesses.

$\mathrm{Na}$ forma de ver de Max Weber, a racionalização compreende desde o plantio em carreiras até a forma sonata nas sinfonias, desde a contabilidade gerencial à liturgia dos cultos religiosos. Engloba a tecnificação do trabalho, a burocratização das relações, a padronização da sociedade, como efeito inevitável da evolução da cultura ocidental. Quando Weber se refere à racionalização no mundo contemporâneo ele tem em mente a importância crescente das instituições formal e substantivamente racionais. A racionalização da ação "é a substituição da submissão íntima dos costumes pela adaptação planejada a uma situação objetiva de interesses... seja racionalizando valores, seja racionalizando os fins ...”.

A racionalização formal-instrumental do Estado, da economia, das organizações e das decisões privadas, vai desembocar no "espírito coagulado" do capitalismo monetarizado, na "jaula de ferro" ${ }^{2}$ da vida juridificada em que estamos contidos e nessa "escura noite polar" quantitativizada que a humanidade atravessa. Significa a submissão da individualidade às regras legais e burocráticas. Uma lógica centrada nos meios, não nos fins. Não se trata de uma escolha consciente, nem de uma forma deliberada de dotar as instituições de maior eficiência, mas uma característica inerente a determinadas instituições. Um dos mais importantes aspectos do processo de racionalização é a substituição impensada do costume antigo; a adaptação deliberada do trabalho e da vida em termos dos interesses imediatos. Outras características são a racionalização consciente dos valores últimos, dos costumes, dos valores afetivos e o ceticismo moral.

O termo racionalização em Weber está referido a ações sociais racionalmente orientadas. É o processo de introdução de racionalidades, ou do que, em diferentes épocas e lugares, julgamos ser racional. Corresponde às racionalidades prática, formal, teórica e substantiva.

No que se refere à racionalidade prática, liga-se à ordenação direta da ação voltada para interesses egoístas e pragmáticos. Aceita o status quo, os valores e as tradições e procura o melhor meio de lidar com eles. Calcula os meios para alcançar os fins. Inclina-se a se opor a todas as orientações baseadas na transcendência axiológica, religiosa, política (utopias) e intelectual (racionalidade teórica); está presente em todas as épocas e culturas, mesmo as

\footnotetext{
${ }^{2}$ Goethe (citado por Weber, 2005).
} 
mais místicas. A racionalização prática implica a subordinação dos indivíduos à realidade dada.

A racionalidade formal concerne às estruturas de dominação (legais, econômicas, científicas e a forma burocrática). Deriva da racionalização instrumental com referência a regras, leis, regulamentos. É referida às normas abstratas, sem conexão com pessoas, a regras universalistas, no sentido em que não considera os interesses e qualidades individuais. O caso típico da racionalização formal é o da observância disciplinada às convenções implicada a dominação burocrática para as organizações e nas "leis de mercado" para a economia.

Já no que toca à racionalidade teórica tem uma influência indireta sobre a ação. É referida à constituição de conceitos abstratos, à atribuição de causalidades e à formação de significados simbólicos. É a faculdade de aquisição de conhecimentos, do pensamento sistemático, dos feiticeiros, sacerdotes, teólogos, filósofos etc. A racionalidade teórica provê a explicação do mundo. Deriva da necessidade metafísica de dar significado à existência e ao universo. A racionalização teórica modifica a vida social, mediante rituais religiosos (racionalização do sobrenatural), por exemplo, ou mediante a fé na ciência (o des-encantamento), podendo dominar o pensamento em uma sociedade ao introduzir padrões de ação tidos como "corretos" ou "lógicos".

A racionalização substantiva abrange a ordenação direta da ação segundo postulações de um conjunto de valores. Compreende os valores comunitários, como a amizade; sociais, como o igualitarismo; e universais, como se pretendem os valores religiosos, éticos e estéticos. É referida à estruturação da sociedade, das comunidades, das organizações, dos pequenos grupos etc. A racionalização substantiva se dá segundo uma direção, pontos de vista fundados na conjugação de valores (ideal-tipo) determinados. É denunciada pelo fato de que cada grupo humano defende seus valores como "racionais", sem atentar para o perspectivismo histórico, como no caso da evolução econômica do Ocidente, em que o que era considerado racional na tradição, tornou-se rapidamente "irracional" no capitalismo moderno.

Weber não "descobriu" o processo de racionalização e os seus efeitos, e também não o fez Kafka, mas como ele, no campo da literatura, Weber sistematizou o conceito e o tornou analiticamente útil. A ideia weberiana de racionalização perpassa o século XX. Está representada na literatura (Brave new world, 1984), no cinema (THX 1138, 2001, Brazil) e, reflexivamente, no pensamento social (Mcdonaldização das relações sociais), o marco da cultura norte-americana. 


\section{0 processo histórico}

Para Weber, a institucionalização da racionalidade não leva ao progresso, mas à unificação sistemática de tudo que é controlável. Leva à emergência de esferas separadas da ciência, da estética e dos valores morais, cada uma delas constituindo uma lógica interna própria, e à consequente perda de significado cultural decorrente da fragmentação das esferas cognitiva, estética e moral do trabalho.

Weber sustentou que o processo histórico é regido por uma série difusa de elementos "não racionais", racionais e irracionais justapostos. Que a realidade é fragmentada e desconexa. As racionalizações são tentativas de dar sentido e orientação a essa não racionalidade, de forma que o racionalismo, como processo histórico, é uma contradição em si mesmo e nenhum elemento unívoco, incluindo o materialismo histórico, é suficiente para explicar como a evolução social acontece.

O processo de racionalização é universal. Pode se dar em qualquer esfera (não só a econômica, como pregam os marxistas), em intensidade variável e de modo diverso. Origina-se em uma constelação de fatores. A racionalização religiosa, por exemplo, é totalmente diferente na cultura chinesa, na hindu, na do Oriente próximo e na cultura europeia-americana. A racionalização se dá tanto na esfera "externa" (organização do mundo legal, política, econômica, da dominação, do conhecimento), como na "interna" (religiosa, ética, estética, erótica).

O processo é multidimensional, constituindo um erro reduzi-lo a uma única dimensão. Por exemplo, a burocratização, característica do modelo ocidental de estrutura administrativa, tem uma dimensão formal, mas não seria possível sem os valores, a pragmática e as teorias que conformam o capitalismo moderno. Por outro lado, as racionalidades se contrapõem. A racionalidade substantiva se opõe à formal, e tal conflito, entre o conservador e o modernizante, é essencial para a compreensão do processo histórico de racionalização no Ocidente.

Os estudos de Weber acerca das peculiaridades da civilização ocidental o levaram a concluir que o processo de racionalização não conseguiu expurgar o aspecto irracional de nossa existência, mas antes consistiu na sua mais radical afirmação. A noção de condicionalidade em lugar da de causalidade é o centro daquilo que Hannah Arendt (2003) denominou "descoberta de Max Weber": a independência das ideias, a autonomia das causas em relação às ideologias que refletem simples relações de produção. 
Em relação ao mundo em que vivemos, à economia e à sociedade atuais, Weber foi buscar a origem da racionalização nos dois pilares da civilização ocidental: a religião e a ciência. Ele procurou demonstrar, contra o materialismo histórico de Marx, que a religião não é uma ideologia, senão que a ética religiosa surgida durante a Reforma contribuiu para o aparecimento do "espírito do capitalismo", como fenômeno que funda o modo de produção contemporâneo. Que a relação de causalidade entre a religião — o luteranismo e o calvinismo - e a vida material é indireta: isto é, que a religião não causa o capitalismo, senão que fornece as condições para que ele se estabeleça na forma que o conhecemos.

No mundo contemporâneo, o espírito objetivo e o espírito subjetivo, embora constituam verso e reverso de uma mesma moeda, permanecem mutuamente excludentes. O que se verificou, diz Weber, foi uma interação entre o espírito e a lógica material, um alimentando o outro, um como condição de possibilidade do outro. A ordenação do pensamento e da ação em formas normatizadas virtualmente substituiu a religião como credo motivacional em grande parte da "civilização avançada". As forças da racionalidade derrotaram a religião. Já quanto à ciência, que o Iluminismo e Marx olhavam como meio de superar a alienação, Weber viu nos seus efeitos, no cientificismo, a transformação da natureza e do espírito em artifício e máquina.

Para sustentar essa posição, ele analisou a trajetória econômica e social que desemboca no capitalismo moderno. Partindo da constatação de que os protestantes eram maioria esmagadora nos momentos e nos lugares em que o capitalismo surgia e se estabelecia, e que auferem mais renda do que os católicos, verificou que tais fatores fizeram com que o seu nível médio de educação aumentasse, permitindo o trânsito acelerado da produção artesanal para a industrial. Esse trânsito se deu quando a ambição do lucro imediato foi substituída pela ambição da segurança da acumulação. O foco do móbil econômico se deslocou, então, para o reinvestimento e para a organização racional da produção, para a tecnificação dos negócios e do trabalho, para o que hoje denominamos logística, marketing, planejamento.

Historicamente, o processo de racionalização econômica levou à eliminação dos recursos (inclusive humanos) ineficientes. O propósito do esforço humano deixou de ser a simples produção e passou a ser o dever de trabalhar, conduzindo ao ascetismo da contenção e do consumo. Esse conjunto de resultantes, Weber chama de "espírito do capitalismo", um fenômeno cuja condição de possibilidade é dada pela "ética protestante".

Nos primórdios evolutivos do capitalismo, a conduta moral dominante implicava adquirir cada vez mais dinheiro como um fim em si, sem nenhuma 
intenção de obter mais utilidade nem outra felicidade do que a de supor ter sido tocado pela graça divina. Confrontando tal conduta com as prescrições religiosas protestantes, Weber deduziu que a noção da impenetrabilidade dos desígnios divinos e a lógica que se segue haviam levado a um imperativo moral de produção e de comércio, a um "capitalismo ascético", só possível pela eticidade do "chamamento" de Deus.

A noção de chamamento está presente tanto no calvinismo - que propõe o esforço humano como uma tarefa para toda a vida, dentro de um campo definido de trabalho - quanto no luteranismo, na ideia de que a eticidade está em servirmos a Deus, realizando as obras para as quais fomos chamados. Para Calvino o trabalho deveria formar uma barreira contra a indolência, contra a ociosidade da nobreza e contra a mendicância. O que ele pregava era uma exacerbação do preceito paulino de que quem não trabalha não deve comer, sendo necessário, portanto, "instruir", isto é, constranger as pessoas ao trabalho, fazer do trabalho um dever de cada um. Já Lutero acreditava que, sendo a profissão uma vocação, não se tem o direito de ignorar o chamado de Deus: deve-se laborar e orar, perseverando na profissão escolhida.

O que a Reforma diz é que seremos salvos pela fé, não pelas obras. Devemos obediência às autoridades. Devemos aceitar as coisas como elas são, uma vez que a distribuição desigual dos bens e da felicidade foi ordenada por Deus. O destino nada tem a ver com o mérito. À racionalização teórica, substantiva e formal, implicadas na Reforma, veio se somar a racionalização prática. Conciliar escolha, vocação e fé só é possível em uma vida ordenada dentro de princípios extremamente rígidos. $\mathrm{O}$ ascetismo - a privação disciplinada - engendra racionalidade, uma forma de encarar o mundo. Desses fundamentos deduz-se a regra de comportamento; organiza-se a vida. Daí o "cálculo e frugalidade" dos primórdios do protestantismo.

A dedução de Weber desta eticidade como condicionante da formação do capitalismo moderno obedece à seguinte linha de raciocínio: o puritanismo está baseado na repressão dos impulsos naturais que acompanham uma racionalização ética rigorosamente fundada na vontade. Mesmo não sendo senhor do seu destino, o homem comum tem necessidade de se assegurar da salvação ("certituto salutatis") e só pode fazê-lo mediante duas ordens práticas de conduta: considerando-se escolhido, vocacionado para servir a Deus e estar entre os que serão salvos, o que lhe impõe combater dúvidas e tentações; e alimentando a própria fé, trabalhando continuamente para aumentar a autoconfiança com a prova da verdade da fé no fruto do trabalho, dádiva de Deus. A ética vocacional assim fundamentada se encaixa à perfeição na mecânica de trabalho ascético, acumulação e reinvestimento que fundam o capitalismo moderno. 


\section{0 trabalho ascético}

Weber concebeu o desencanto religioso e o cientificismo como causa eficiente do processo de racionalização no Ocidente. Mas o efeito sobre a vida econômica foi involuntário. Não foi o protestantismo que causou o capitalismo. As consequências da Reforma eram imprevistas: o que ocorreu foi uma dupla implicação, uma coincidência espaço-temporal entre a cultura do ascetismo religioso e as condições objetivas das transformações do capitalismo. O efeito da dupla implicação sobre o trabalho é evidente no ethos da empresa burguesa racional e da organização do trabalho, que são puritanos na origem. Não no sentido de que uma e outra sejam exclusivas do capitalismo moderno, mas no de que são as suas condições de possibilidade.

A desumanidade extrema da doutrina protestante levou a um individualismo religioso. O crente estava só: nem a Igreja, simples congregação, nem a comunidade religiosa, em que os pares concorriam pelos poucos lugares no céu, podiam socorrê-lo. Ele não podia esperar nada, nenhum auxílio, nem mesmo de Deus, uma divindade oculta e enigmática (absconditus). Cada um devia acreditar ter sido escolhido por Deus, uma vez que quem não crê em si mesmo não pode acreditar que Deus creia nele. Acreditando em si, cada um devia dedicar-se ao máximo ao trabalho, o meio para adquirir a independência e o sucesso na vida terrestre, que não é, certamente, garantia de salvação, mas um signo promissor da mercê celeste.

O fim do esforço disciplinado e honesto como fonte de valor e dever moral determinou, em um processo de autoalimentação, a decadência da ética do trabalho, na medida em que os poderes valorativos a ela atribuídos se tornaram externos e estranhos ao trabalhador. Na formação do capitalismo moderno, o trabalho serviu para dar sentido espiritual a um mundo que, segundo a doutrina calvinista da predestinação, é essencialmente sem sentido. O trabalhador não visava outra coisa além de reproduzir a vida, mas como a vida consome os frutos do trabalho, tratou então de acumular, de conter o consumo, de economizar vida e trabalho.

O entesouramento produziu o sentimento de que o trabalho é produtivo; a sabedoria da cigarra imprevidente e da formiga ascética. No capitalismo primitivo, o trabalho era um meio para a vida e para a previdência. No capitalismo moderno, graças ao ascetismo protestante, o trabalho se tornou um fim em si mesmo, um dever; não uma disposição prática.

Há muito a ética protestante do trabalho desapareceu. O que restou foram as suas sequelas: a instrumentalização de tudo, a dessacralização da vida, a redução do social a sistemas e estruturas institucionalizadas, a 
taylorização do esforço produtivo, mediante a tecnificação, a rotinização, o declínio do próprio trabalho enquanto instrumento para alcançar objetivos considerados desejáveis (status, poder, riqueza...). Paradoxalmente o ascetismo religioso do trabalho, que deveria servir à maior glória de Deus, ao não consumo, ao reinvestimento, deu a condição de possibilidade da abundância. Sob a égide do protestantismo, o trabalho se especializou, renunciou à universalidade, limitou-se à vida funcional. Tornou-se um dever moral estrito, cada trabalhador devendo se comportar como um monge, com uma vida regulada, sem a ambição de gozar do fruto do seu esforço. O trabalhado passou a ocupar o lugar central na vida, um derivativo aos escapismos religiosos da confissão, da mediação da Igreja, controladora da esperança transcendente.

No protestantismo, graças à tradução que Lutero faz do Eclesiastes, a noção de vocação ganhou o sentido de profissão, de ofício. O título da obra seminal de Weber tanto pode ser entendido como "a política como profissão" ou "a política como vocação". Beruf, a palavra alemã para "toda sorte de atividade diretiva autônoma" se refere tanto à conquista quanto ao exercício da direção de si mesmo. Com a alteração denotativa do conceito, o controle regular do estado de graça passou ao crente individual, deixando de lado a ideia do controle externo, pelos sacramentos mágicos ou pelas eventuais recompensas extraterrenas das boas ações. A sacralização do trabalho consolidou o entendimento de que o ofício é um chamado e favoreceu o autopoliciamento do trabalhador. A passagem da organização patriarcal do trabalho para a organização capitalista do trabalho desvalorizou o ofício como vocação ou profissão, tirando o sentido religioso do trabalho puritano.

A recusa ao trabalho veio a ser sintoma da ausência da graça (Diggins, 1999)

na concepção cristã o trabalho representava o pagamento do pecado, um ato de expiação que sugere necessariamente aflição e miséria. Com o calvinismo, o trabalho teve uma ética e uma finalidade espiritual, embora mergulhada na angústia. Mas com o declínio da crença religiosa... o trabalho uma vez mais se tornou penoso... sem relação com os mais altos valores espirituais.

No início da modernização do capitalismo, os camponeses preferiram cada vez mais se assalariar, deixando de ser pequenos proprietários eternamente em dificuldades. Preferiram uma relação de trabalho segura ao ganho material imediato. A divisão capitalista do trabalho, a diferenciação profissional e a especialização se conformaram perfeitamente à ética puritana. 


\section{0 trabalho burguês}

Com o aburguesamento, a vida de trabalho perdeu a memória de vocação: deixou de ser um mandamento divino. Não há uma estrutura racional preexistente, natural. O trabalhador é forçado a uma escolha que, no mundo desencantado, nem a religião nem a ciência podem informar.

A responsabilidade deriva da consciência sobre a necessidade da escolha entre valores últimos e da própria possibilidade de escolha entre meios alternativos para os fins perseguidos, consideradas suas consequências. A escolha entre valores implica uma renúncia, num mundo onde nenhuma esfera de valores pode, justificadamente, legitimamente, se impor sobre outra. Em um mundo onde inexiste uma esfera superior - religiosa, científica, filosófica - que possa arbitrar os conflitos valorativos.

Sob o peso do desencanto e do cientificismo, o autocontrole da consciência deixou de ser o móbil do trabalho. O êxito material confundiu-se com a salvação religiosa e o dinheiro assumiu uma qualidade mágica. O mundo material perpetuou a necessidade de trabalhar quando o idealismo ascético já o havia abandonado.

No texto sobre a política como vocação e a ciência como vocação, Weber (1974) procurou demonstrar que os atributos que uma pessoa deve ter para exercer a política e a ciência como ofício derivam da coerência entre o trabalho, a personalidade e o modo de vida em que "cada um acha o demônio que tem na mão e os fios de sua vida e a ele obedece". Ele entendia o trabalho moderno como ofício, "a especificação, a especialização e a combinação de prestações que permitem a uma pessoa assegurar-se chances de abastecimentos e aquisições". O trabalho burguês já não oferece condições para a realização de uma vocação; apenas os meios necessários para viver. Permite a sobrevivência, mas não dá o sentido da vida.

A combinação da ética protestante com as circunstâncias histórico-econômicas trouxe à sociedade um novo geist, o espírito do capitalismo moderno. Com a racionalização da vida social, a ética fundada na religiosidade se transferiu à lógica produtivista do trabalho, que desemboca no estilo, ou na falta de estilo, do modo de vida burguês. Uma nova combinação, entre a lógica do ganho econômico e a da forma de viver da classe economicamente mais bem colocada, traz à renúncia do trabalho gratificante. $\mathrm{O}$ trabalhador comum busca status (a posição do indivíduo ou do grupo aos olhos dos demais), emulando o estilo de vida da classe imediatamente superior.

Ao contrário da "consciência de classe" a consciência de status se move de cima para baixo. A ostentação da riqueza e a possibilidade de desperdício 
são mais valorizadas do que a produção honesta. Ao mesmo tempo o sistema força para o ascetismo da renúncia e o do trabalho, do "dever" que substitui o ascetismo religioso, da necessidade de consumir e de manter o mecanismo funcionando.

Os indivíduos trabalham por diferentes razões. Weber distingue quatro motivações analiticamente diferentes para o trabalho: a da ética econômica tradicional; a da ética econômica carismática; a da ética prática racional; e a da ética econômica racional.

A ética econômica tradicional santificava os meios habituais de satisfazer as necessidades humanas. Os trabalhadores imbuídos do espírito tradicional tendem a ver o trabalho como um mal necessário. Por isso, tão logo as necessidades básicas são satisfeitas, desaparece a motivação para o trabalho. Nenhum incentivo material afeta essa situação. Na perspectiva tradicional, menos trabalho vale mais do que ganhos maiores, isto é, dado um aumento na remuneração o trabalhador se dedicará proporcionalmente menos ao trabalho.

Na visão da ética carismática, dos "capitalistas aventureiros", dos "empresários heroicos", o trabalho é autônomo. A racionalidade é a do fim colimado: em geral o lucro e o poder. Tão logo o fim seja alcançado, a motivação desaparece ou se dirige para um fim diverso.

A ética tradicional justifica o trabalho em que prevalece o cálculo das vantagens pessoais. O esforço que se volta para a autossatisfação, para a satisfação dos interesses individuais. A ética econômica racional, correspondente ao "espírito do capitalismo" moderno, toma o trabalho como um dever, uma obrigação positivamente valorada como um fim em si mesmo. Derivada do protestantismo, a sua motivação reside na intensidade e na estabilidade do esforço suficiente para sobreviver aos requisitos e pressões do capitalismo moderno.

O trabalho moderno, que começou como disciplina moral voluntária, continuou a dominar as vidas humanas, mas agora pelo mecanismo, não mais pelo sentido. A organização do trabalho e a tecnologia contemporânea encorajam a secularização e o desencantamento do mundo, pois elas expõem cada vez mais campos da sociedade às normas da sociedade técnico-instrumental.

O capitalismo se tornou inimigo do trabalho. Não só porque o explora, mas porque o descarta. Primeiro espiritualmente, com o desencanto, depois materialmente, com a tecnologia. A racionalização nos levou à servidão da máquina, ao sem sentido do esforço produtivo ao fim da “...inclinação para o trabalho ...que deve ser determinada tanto por um forte autointeresse no resultado, quanto por coação direta ou indireta". A motivação baseada em valores abstratos (religiosos) se perdeu quando não mais se pode identificar o trabalho com o seu resultado material ou espiritual. 


\section{O trabalho desencantado}

Por desencantamento do mundo, Weber entende o longo processo de abandono do pensamento mágico, a dessacralização, a racionalização promovida pelo cristianismo e levada a termo pela ciência. O desencantamento corresponde a uma regulação da vida cotidiana fundada no compromisso dos indivíduos com seus valores. Desemboca em uma tensão entre a perda da liberdade da submissão aos valores mundanos e os valores últimos da moralidade. Fragmentada, a vida consciente, presa entre a responsabilidade e a convicção, entre o justo e o sagrado, perde sentido, torna-se paradoxal.

A racionalização é o processo de difusão da racionalidade da ação em vários âmbitos da vida social. Implica a passagem de um mundo encantado, orientado para a magia, para um mundo desencantado, despido de inconsistências lógicas. Mas a racionalização não é um processo unívoco. Ao contrário, é diferente para cada esfera da ação. A racionalização jurídica, por exemplo, é diferente da econômica. A especificidade de cada esfera determina os significados e a forma como são encadeados.

Na perspectiva weberiana, o fenômeno do trabalho se coloca aquém da discussão filosófica. A compreensão do que vem a ser o trabalho deve considerar a sua racionalização em três chaves distintas. De um lado, a racionalidade econômica impõe uma eficácia produtiva que desconhece os limites do sentimento e da integração social. De outro, a racionalidade social impele para uma pauta de coexistência. Por fim, a racionalidade privada clama pela possibilidade, ainda que limitada, de autorrealização.

É o confronto de racionalizações que rege o trabalho burguês. A racionalização do cálculo e da controlabilidade, a zweckrationalität, ou racionalidade relativa aos fins que são meios para outros fins e que se opõe a uma racionalidade que se pauta pelos valores. Opõem-se a racionalidade instrumental e a wertrationalität, ou racionalidade absoluta dos valores indicativos das preferências que, idealmente, deveria reger a vida social.

A maneira de racionalizar os negócios e o trabalho no que Weber denominou de "capitalismo vitorioso" é baseada em quatro categorias institucionais: separação entre vida doméstica e a vida no trabalho, com a industrialização; a contabilidade racional, que permite medir objetivamente o resultado do esforço produtivo; a possibilidade da venda livre da força de trabalho, com a formação do operariado e do proletariado; a organização racional do trabalho livre em função da dinâmica do mercado.

A característica específica do capitalismo moderno, que o distingue das outras formas de capitalismo, "é a organização racional do trabalho com base 
na tecnologia racional". Weber vê a máquina como a objetivação da disciplina, do cálculo e da organização racional. Para ele é a cultura racionalizada que cria a tecnologia, enquanto para outros, para os marxistas, por exemplo, o processo de racionalização do trabalho se dá pela força das operações especializadas requeridas pela máquina.

Para que o sistema capitalista seja funcional é preciso que seus processos, normas e estruturas sejam previsíveis, calculáveis e neutros em relação aos indivíduos particulares. Por esse motivo, quanto menos qualificado é um operário, mais ele é suscetível de ser substituído por uma máquina, ao passo que os operários mais qualificados serão cada vez mais indispensáveis e, portanto, mais protegidos contra a racionalização tecnológica.

A racionalização nem sempre é negativa, nem o capitalismo o único sistema perverso. Depreende-se das observações de Weber ao examinar a racionalização burocrática que quanto mais desumanizada, quanto maior a eliminação dos sentimentos e dos interesses pessoais, mais justas e imparciais são as relações de trabalho. Ele não via nenhuma diferença substancial entre a racionalização advinda da empresa capitalista e a inerente ao controle burocrático do Estado socialista. A sorte dos trabalhadores, argumentava, não é nada diferente seja a mina privada ou estatal. A apropriação do produto do trabalho, tanto no sistema capitalista como no sistema socialista, age contra a racionalização econômica. No sistema capitalista, a apropriação pela empresa/proprietário implica o desinteresse do trabalhador em alcançar um rendimento ótimo. No sistema socialista, a apropriação pelo Estado/trabalhadores, alimenta o conflito entre o interesse próprio - maior conforto e menor produtividade do trabalho tradicional - e o rendimento ótimo do trabalho. De um lado temos uma estrutura em que a diversidade e a responsabilidade de ofício são acompanhadas pela injustiça e pela ineficiência, de outro, um quadro em que a impessoalidade e a eficiência são acompanhadas pela padronização e pela infantilização das relações de trabalho.

\section{Especialistas sem coração}

O processo de redução lógica, detectado por Weber, não se extinguiu no século XX. Estende-se hoje a esferas que ele não teria imaginado. Passamos pela organização da guerra, pela burocratização das artes e dos esportes. Vivemos a era da racionalização do corpo, do ideal da aparência. E prosseguimos. Afi- 
nal o que seriam os amontoados de filmes, terapias, instrumentos, congressos e literatura técnica senão a racionalização psicológica e cinética do sexo? ${ }^{3}$

A racionalização prática do trabalho é evidente na subordinação dos interesses mais altos da vida pessoal (autorrealização, serenidade, fruição estética...) e da vida social (amizade, segurança, fidúcia... ) do trabalhador à realidade dada, aos interesses imediatos do establishment, às formas de viver burguesas, às ambições inautênticas.

A racionalização formal se manifesta nas estruturas de dominação nas ascendências normativas, nas hierarquias rígidas, nos planos de carreira... - e em todas as regras que cerceiam o trabalho, as formas de se trabalhar, e a vida funcional e econômica do trabalhador.

A racionalização teórica se manifesta na aceitação passiva da naturalização de esquemas meramente históricos ou de dominação, como o do "princípio" de liderança ou a da divisão da filiação política em esquerda e direita. Na ideia de que tais esquemas têm causalidades lógicas inelutáveis e de que os significados meramente simbólicos, como os do êxito na carreira funcional, são justificáveis teoricamente ("cientificamente").

A racionalização substantiva está presente na crença de que o trabalho é essencial à vida espiritual, no opróbrio dos que não trabalham, na ideia de que o trabalho é um fenômeno antropológico, e não, como de fato acontece, uma necessidade econômica ausente em muitas culturas e em muitas épocas.

Os conceitos de racionalidade e de racionalização possibilitaram a Weber demonstrar a importância das ideias na determinação das ações humanas e como o processo evolutivo do Ocidente alterou não só a organização do trabalho, mas, também, o significado do trabalho para a personalidade humana. A racionalização da vida social levou ao desencantamento do mundo, à instrumentalização das ações, à existência sem propósito. A economia deixou de ser ascética, a religião deixou de orientar a vida e o trabalho deixou de ter sentido: tornou-se algo naturalizado, que os indivíduos e a sociedade sequer tentam justificar. A racionalização, que havia derrotado a religião, derrota agora, no capitalismo moderno, a razão, a "herdeira sorridente do iluminismo". O produtivismo capitalista, nascido de um ascetismo religioso, se perpetuou em virtude de uma lógica materialista. Sem dúvida o capitalismo produziu a abundância, mas o fez à custa do trabalho mortificante, porque, para serem utilizados e consumidos, os produtos do trabalho têm que ser comprados.

\footnotetext{
${ }^{3}$ Weber (1974) dá o erotismo como válvula de escape do "mecanismo da racionalização".
} 
O empregado que repete todos os dias as mesmas operações, o faz, para Weber, por diversas razões. O que legitima a ordem no trabalho se enquadra em uma tipologia conhecida (carismática, tradicional etc.). O fato de a vinculação funcional do trabalhador ter se alterado, não ser ou não ser mais dominantemente tradicional, ser dominantemente burocrática, não perde validade com a alternância da vinculação. O trabalhador - empregado ou profissional - pode ter a sua vinculação legitimada por qualquer dessas ordens e por outras, não descritas por Weber. O que importa é que ele obedecerá não necessariamente à ordem que crê legítima, mas a que crê inevitável.

A economicidade acrítica do neoliberalismo levou a reduzir toda a racionalidade à racionalidade maximizadora. Buscou-se, busca-se, o ótimo não só dos bens materiais, mas do poder, dos afetos e de tudo que possa parecer desejável. Ora, para Weber só a racionalidade instrumental é maximizadora. Há todo um campo do racional e do não racional que nada tem a ver com a maximização. O ótimo social é função de especificidades de lugar e tempo: não há um ótimo cultural, e não há regra externa para o ótimo vital. A secularização do comportamento ascético no trabalho se tornou uma necessidade material inelutável. O que Weber critica não é esta inevitabilidade, mas a ideia do trabalho e da vida como mero "esporte", como exercício lúdico e sem sentido, denunciado por Nietzsche, de quem Weber foi leitor. O trabalho tornado uma compulsão em vez de uma vocação.

A religião havia prometido salvar a humanidade, a razão, libertá-la da dominação da ignorância. A racionalização levou-nos primeiro à desmistificação, depois ao desencantamento do mundo e, por fim, à idolatria pragmática do real concreto. O que temos hoje é a vida consumida pelo trabalho. Um trabalho exclusivamente ligado às condições técnicas e econômicas da produção mecânica e mecanicista. Um trabalho que arruína todas as outras esferas do viver; que erigiu um mundo onde todos os trabalhos são forçados, onde todo esforço humano se concentra na reprodução do mundo Um trabalho que celebrou o pacto fáustico com o diabo por maiores riquezas, condenado à insatisfação eterna da plenitude jamais realizada.

Se Weber pudesse analisar o trabalho dos executivos das grandes corporações contemporâneas, teria dito a mesma coisa que disse do trabalho do político: que é intrinsecamente trágico, que possibilita o uso despótico do poder, que exercer tal atividade é abdicar de toda pretensão à inocência e à virtude e aceitar os encargos da responsabilidade e da presença traiçoeira do mal. Identificaria em nós os trabalhadores que ele descreveu como "especialistas sem visão e sensualistas sem coração - nulidades que imaginam ter atingido um nível de humanidade nunca antes alcançado". 


\section{Referências}

ALEXANDER, Jeffrey C. The promise of a cultural sociology. In: MÜNCH, Richard; SMELSER, Neil J. (Eds.). Theory of culture. Berkeley, CA: University of California Press, 1992.

ARENDT, Hannah. A condição humana. Tradução de Roberto Raposo. São Paulo: Forense Universitária, 2003.

ARNASON, Johann P. Rationalisation and modernity: towards a culturalist reading of Max Weber. La Trobe University, s.d. p. 6.

COHN, Gabriel. Crítica e resignação: Max Weber e a teoria social. São Paulo: Martins Fontes, 2003. p. 229.

DIGGINS, John Patrick. Max Weber, a política e o espírito da tragédia.Tradução de Lizt Vieira e Marcus Lessa. Rio de Janeiro: Record, 1999. 375p.

ELSER, Jon. Rationality, economy and society. In: TURNER, Stephen (Ed.). The Cambridge companion to Weber. Cambridge: Cambridge University Press, 2000. p. 22.

FATHERSTONE, Mike. Cultural production, consumption and development of the cultural sphere. In: MÜNCH, Richard; SMELSER, Neil J. (Eds.) Theory of culture. Berkeley, CA: University of California Press, 1992.

GERTH, H. H.; WRIGHT MILLS, C. Ensaios de sociologia. Rio de Janeiro: Zahar, 1974.

HALTON, Eugene. The cultic roots of culture. In: MÜNCH, Richard; SMELSER, Neil J. (Eds.). Theory of culture. Berkeley CA: University of California Press, 1992. p. 49.

KALBERG, Stephen. Max Weber's types of rationality: cornerstones for the analysis of rationalization in history. The American Journal of Sociology, v. 85, n. 5, p. 1145-1179, mar. 1980.

. Culture and the locus of work in contemporary Western Germany: a Weberian configurational analysis. In: MÜNCH, Richard; SMELSER, Neil J. (Eds.). Theory of culture. Berkeley, CA: University of California Press, 1992.

MARX, Karl; ENGELS, Friederich. A ideologia alemã. Disponível em: <www.pstu. org.br/biblioteca/marx_ideologia.pdf $>$.

MOTTA, Paulo Roberto de Mendonça. A ciência e arte de ser dirigente. Rio de Janeiro: Record, 1991.

MULLER, Hans Peter. Trabalho, profissão e "vocação"; o conceito de trabalho em Max Weber. In: MERCURE, Daniel; SPURK, Jan (Org.). O trabalho na história do 
pensamento ocidental. Tradução de Patrícia Chittoni Ramos e Sônia Guimarães Taborda. Petrópolis: Vozes, 2005. p. 237.

OAKES, Guy. Weber and Rickert: concept formation in the cultural sciences. Cambridge, MA: MIT Press, 1988.

PAIVA, Valéria. Tragédia da cultura e modelagem da identidade: uma leitura de Weber e Simmel. Sinais Sociais, v. 1, n. 3, p. 168, jan./abr. 2007.

PARSONS, Talcott. Max Weber: the theory of social and economic organization. New York: The Free Press of Glencoe, 1964.

RITZER, George. The Mcdonaldization of society. Journal of American Culture, n. 6, p. 100-107, 1983.

ROGUE, Cristophe. Le travail. Paris: Armand Colin, 2005. p. 124.

SCAFF, Lawrence A. Fleeing the iron cage. Berkeley: University of California Press, 1989. p. 223.

. Weber on the cultural situation of modern age. In: TURNER, Stephen (Ed.).

The Cambridge companion to Weber. Cambridge University Press, 2000.

SCHLUCHTER, Wolfgang. Politeísmo dos valores. In: SOUZA, Jessé (Org.). A atualidade de Max Weber. Brasília: Universidade de Brasília, 2000.

SICA, Alan. Rationalization and culture. In: TURNER, Stephen (Ed.). The Cambridge companion to Weber. Cambridge: Cambridge University Press, 2000.

TENÓRIO, Fernando Guilherme. Permanencia del modelo weberiano. Revista Internacional de Ciências Administrativas, Instituto Internacional de Ciências Administrativas, v. 47, n. 3, 1983.

THIRY-CHERQUES, Hermano Roberto. O trabalho como profissão: a racionalidade do compromisso. Revista de Administração Pública, v. 36, n. 6, p. 879-904, 2002.

WEBER, Max. The protestant ethic and the spirit of capitalism. Nova York: Charles Scribner's Sons, 1950.

. Economía y sociedad. México: Fondo de Cultura Económica, 1964.

. História geral da economia. São Paulo: Mestre Jou, 1968.

. A política como vocação. A ciência como vocação. In: GERTH, H. H.; WRIGHT MILLS, C. Ensaios de sociologia. Rio de Janeiro: Zahar, 1974a.

. Rejeições religiosas do mundo e suas direções. In: GERTH, H. H.; WRIGHT MILLS, C. Ensaios de sociologia. Rio de Janeiro: Zahar, 1974b. 
. Economia e sociedade. Tradução de Regis Barbosa e Karen Elsabe Barbosa. Brasília: Universidade de Brasília, 2000.

. A ética protestante e o espírito do capitalismo. Tradução de M. Irene Szmrecsányi e Tamás Szmrecsányi. São Paulo: Pioneira Thomson Learning, 2005. 